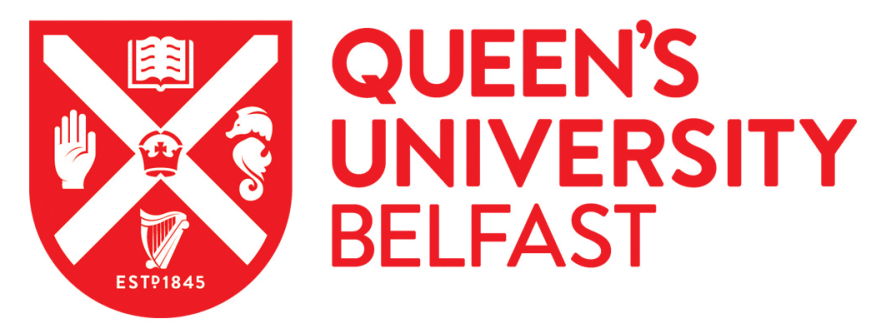

\title{
Development of a teaching model to advance skills in industrial pharmaceutical formulation and regulatory aspects
}

\begin{abstract}
Laverty, G., Belaid, L., Coulter, C., \& Porter, S. (2018). Development of a teaching model to advance skills in industrial pharmaceutical formulation and regulatory aspects. Currents in Pharmacy Teaching and Learning. https://doi.org/10.1016/j.cptl.2018.07.011
\end{abstract}

\section{Published in:}

Currents in Pharmacy Teaching and Learning

\section{Document Version:}

Peer reviewed version

Queen's University Belfast - Research Portal:

Link to publication record in Queen's University Belfast Research Portal

\section{Publisher rights}

Copyright 2018 Elsevier.

This manuscript is distributed under a Creative Commons Attribution-NonCommercial-NoDerivs License

(https://creativecommons.org/licenses/by-nc-nd/4.0/), which permits distribution and reproduction for non-commercial purposes, provided the author and source are cited.

\section{General rights}

Copyright for the publications made accessible via the Queen's University Belfast Research Portal is retained by the author(s) and / or other copyright owners and it is a condition of accessing these publications that users recognise and abide by the legal requirements associated with these rights.

Take down policy

The Research Portal is Queen's institutional repository that provides access to Queen's research output. Every effort has been made to ensure that content in the Research Portal does not infringe any person's rights, or applicable UK laws. If you discover content in the Research Portal that you believe breaches copyright or violates any law, please contact openaccess@qub.ac.uk. 
Title: Development of a Teaching Model to Advance Skills in Industrial Pharmaceutical Formulation and Regulatory Aspects.

\begin{abstract}
Background and purpose. To design and critically evaluate a laboratory-scale pharmaceutical formulation practical that enables pharmaceutical science students to develop work-based skills relating to industrial pharmacy such as problem solving, pharmaceutical calculations, research, legal checking, communication, practical aptitude, handling of medicinal products, record keeping and ability to interpret, analyze and report data.
\end{abstract}

Educational activity and Setting. Nine laboratory practical sessions were designed whereby students formulated a range of dosage forms and conducted corrective and preventative actions (CAPAs) exercises. A master batch formula outlined the specifications for each product and a practical sheet was provided for the students to record their activities. Student evaluation of the exercise was performed via a self-administered 17-item questionnaire in the final week.

Findings. Twenty-four students completed the workshops over two year groups (2015 year group $\mathrm{n}=11,2016$ year group $\mathrm{n}=13$ ). The mean score across both groups was 15.6 out of 20 . The questionnaire had a $100 \%$ response rate and the majority of students agreed that the classes were a useful teaching method and that they fostered key skills required for pharmaceutical formulation and regulation.

Summary. Laboratory classes effectively delivered course content relating to industrial-based pharmaceutical formulation and helped to develop relevant skills.

Keywords: Pharmaceutics, Industrial, Formulation, Dosage forms, Laboratory skills

\title{
Disclosure statements
}

Financial disclosures: None to declare 
Conflicts of interest: None to declare

Specific Contribution to Literature: This paper outlines the design and implementation of a teaching model aimed at improving student development and learning outcomes in the context of pharmaceutical formulation in an industrial pharmacy context. We believe it to the first recorded example of this kind. Previous research has focused on teaching within a clinical context whereby a student formulates a medicinal product based on the direction of a prescription as would be encountered in community and hospital practice. For industrial pharmaceutical formulation a master batch record, designed by the authors, provides guidance as to what medicinal product should be manufactured, with the student is required to check its check its legal and formulation particulars are correct. Overall this teaching model provides work-based learning in a laboratory environment with emphasis on the key skills required to work within a formulation unit of a pharmaceutical company.

\section{Background and purpose}

Pharmaceutical formulation is the process whereby different chemical substances, including active drug(s) and excipients, are combined to produce a final medicinal product. The majority of medicinal products are manufactured on a large-scale by pharmaceutical companies under strictly regulated conditions of cleanliness and quality in line with Good Manufacturing Practice (GMP) requirements. Small-scale manufacture occurs less frequently but still remains a vital component of pharmaceutical research and development, most commonly utilized for testing the compatibility of new active ingredients with a range of possible excipients or trialling a new formulation for an existing drug. This process is referred to as pre-formulation. It is important pharmaceutical scientists understand how different types of medicines are prepared, allowing them to appreciate how the physicochemical properties of the drug(s) relate to the overall properties of the formulation and how the medicine is delivered to the patient. The General Pharmaceutical Council (GPhC) who are responsible for the accreditation of pharmacy degree programs in the United Kingdom (UK) require students to show how pharmaceutical principles relate to formulation, preparation and packaging of medicinal products including pre-formulation studies. ${ }^{1}$ They also stipulate that students should demonstrate knowledge of 
quality assurance processes relating to raw materials and medicinal products. The PharmD program in the United States has similar requirements relating to students acquiring skills in pharmaceutical calculations and development of quality standards for drug products. They also require laboratories to be suitable for skills practice, demonstration, and competency evaluation. ${ }^{2}$

The objective of this study was to design and evaluate a laboratory practical that would allow level 2 undergraduate students enrolled in the Bachelor degree (BSc) in Pharmaceutical Science to gain experience in the necessary skills and learning outcomes (Table 1) required to prepare medicines, in line with industrial pharmacy requirements. The hypothesis of this study was that pharmaceutical formulation and its associated skills could be effectively enhanced through a laboratory-based practical. The aims of our project were to design, implement, and evaluate the laboratory practical as a method for teaching undergraduate pharmaceutical science students about the importance of formulation and regulatory issues within the pharmaceutical industry. We anticipated that students would also develop a range of work-based skills and competencies relating to problem solving, pharmaceutical calculations, research, legal checking, communication, practical aptitude, handling of medicinal product, record keeping and ability to interpret, analyze and report data.

\section{Educational activity and Setting}

The laboratory class formed part of the compulsory Industrial Pharmaceutics module and encompassed $15 \%$ of the overall score for this module. There were nine weekly classes of 4.5 hour duration in the first semester of the BSc Pharmaceutical sciences (Table 2). This included an introductory week focusing on exercises relating to pharmaceutical calculations, labeling, weighing and use of pharmacopoeia and reference texts to deduce information such as product formulas and solubility of raw materials. For subsequent weeks (2-8) the students were expected to formulate two products via a skills based practical coursework assessment . They were provided with the name of each formulation they were expected to manufacture a week in advance to allow self-study. Products studied are commonly sold or prescribed to patients in a community pharmacy environment, for 
example: ibuprofen suspension (anti-inflammatory, antipyretic, painkiller); hydrocortisone acetate and cinchocaine hydrochloride suppositories for haemorrhoids and $\mathrm{O} / \mathrm{W}$ cream containing mepyramine maleate for insect bites and stings. These drugs and formulations are encountered throughout the BSc Pharmaceutical sciences degree pathway serving as model drugs and formulations for teaching and learning. Oral presentations (Powerpoint form of 40 minute duration) were provided by the academic lead at the beginning of each laboratory class when a student encountered a new formulation (weeks $1,2,6,8)$. These detailed importance aspects of their manufacture, safety considerations, their physiochemical properties and clinical use. The students were presented with a paper copy of the master batch formula (Figure 1) and as the formulation scientist they were expected to check its legal particulars were correct. Master batch formulas were designed to include particulars deemed necessary by the Rules and Guidance for Pharmaceutical Manufacturers and Distributors (Orange Guide) 2015. ${ }^{3}$ Three members of staff acted as qualified persons and requested that the formulation scientist (student) designed and recorded the raw materials required on their master batch formula based on product formulae contained within reference sources (e.g. pharmacopoeia if an official product) or outlined in the course manual if it was an unofficial product. The student was expected to record the function, batch number and expiry date of each raw material as stated on its respective label. Any errors were to be highlighted to the qualified person and the student was expected to be specific with regards to their amendment. Once completed the master batch formula was checked and signed by the qualified person. This is synonymous with the role of the formulation scientist and qualified person within the pharmaceutical industry. Students were then required to manufacture the product and label it. Weighing and measuring of all active ingredients was required to be recorded on an individual weight ticket attached to the practical worksheet and the student was required to record the date, equipment balanced used, equipment serial number, material and weight of drug (Figure 2). These were checked, stamped with the company stamp detailing the correct date of manufacture, signed and dated by the member of staff. This endorsement occurred across the ticket as is common within industrial pharmacy practice to ensure the label could not be tampered with undetected. The product and worksheets were submitted at the end of class to be assessed by staff. 
Most products allowed for a non-assessed introductory week. The second week was assessed and contributed to the final coursework mark. In both weeks the students formulated a product that was graded according to a defined marking scheme (Table 3). Individual written feedback and comments were provided on the master batch formula and practical worksheet and returned to the student on a weekly basis (within 48 hours). It was important that feedback was timely given that this was a continuous assessment. This allowed students to learn from initial mistakes in the first week for that particular product (oral liquids, suppositories, emulsions). The feedback provided enabled the students to address specific errors ahead of the assessed second week. As outlined by Lizzio and Wilson, the aim of feedback is to reduce the gap between the actual performance level and the desired learning outcomes. ${ }^{4}$ Continuous assessment is more reliable to analyze student's capabilities and according to Brown provides an indirect measurement of student's ability to manage time and stress. ${ }^{5}$ This is important in pharmaceutical formulation given that scientist are often working to strict deadlines for manufacture and release of product batches. Three staff members (academic, technician, $\mathrm{PhD}$ student) supervised and assessed the practical.

The pharmaceutical formulation course manual (available upon request) was designed in advance of the laboratory session. The same venue was to hold at least 13 students (2015 year group $n=11,2016$ year group $\mathrm{n}=13$ ) with computer/Powerpoint and audio/microphone facilities for staff presentations. Sufficient space was required to allow students to formulate their product and complete the associated paperwork. Each student had a computer within their designated laboratory space which served as a means to access reference texts, for example the British Pharmacopoeia (BP), in electronic form. These texts were subscribed to by the University library and a hard copy of the BP was also available should the students prefer to use this. Each computer workstation was linked to a designated label printer. Students were able to complete and print their labels using a template predesigned on Microsoft Publisher 2013 (Figure 3). Labels were devised based on best practice guidance on the labeling and packaging of medicines and included information deemed critical by the UK Medicines and Healthcare products Regulatory Agency (MHRA) for the safe use of medicines. ${ }^{6}$ Students were advised at the beginning of each class with regard to safety issues. Control of Substances Hazardous 
to Health $(\mathrm{COSHH})$ forms were also produced and signed by the staff lead and safety officer in advance of each practical. ${ }^{7}$ Laboratory equipment required for each practical are outlined in Table 4. Their intended use was detailed fully in pharmaceutical formulation course manual, along with photos to allow students to identify each.

In week nine of the laboratory session students were required to perform a corrective and preventive actions (CAPAs) exercise. CAPAs are utilized within the pharmaceutical industry to improve an organization's processes in line with the regulatory requirements of the International Conference on Harmonization (ICH) guidance on quality risk management (ICH Q9), ${ }^{8}$ and pharmaceutical quality system (ICH Q10). ${ }^{9}$ They serve as a risk assessment and are performed to eliminate causes of nonconformities by proposing immediate action to resolve issues that may impact quality, patient safety or prevent the release of a medicinal product batch. Such errors should be identified as soon as possible recognizing that quality is built into each stage of the manufacturing life cycle in line with GMP requirements, ${ }^{10}$ and quality by design principles. ${ }^{11}$ Within this paper-based, non-practical, exercise the student acted as the qualified person identifying errors within the manufacturing batch records, practical work sheet and formulated product. It serves as a tool to assess student's ability to identify errors in paperwork using a range of formulations similar to what they would have developed in the previous eight weeks. Students rotated around three work stations relating to each product (oral solution, suppositories and cream emulsion). They were assessed on their ability to spot three intentional mistakes within each medicinal product and 10 minutes was allowed at each station. It was optimal to place the CAPAs exercise as the final assessed week as it represented a collection of all knowledge encountered since the beginning of the laboratory practical session.

A comprehensive marking scheme was developed to define the performance criteria and increase the consistency of staff marking (available upon request). Four main criteria were assessed based on the learning outcomes highlighted in Table 1 with focus on accuracy within the master batch formula, the practical worksheet, the label and the quality of the final medicinal product. Each product was assigned a maximum score of 20 . In the majority of cases failure to identify a legal and regulatory 
error, for example a missing equipment serial number, resulted in a deduction of one mark. Major errors which severely compromised patient safety, for example those relating to the concentration of active ingredient and therefore incorrect strength of final formulation, resulted in a deduction of five marks. Examples are provided in Table 2. Individual mean product scores and overall mean scores were analyzed statistically using a two-tailed, one-way Analysis of Variance (ANOVA) with a TukeyKramer multiple comparisons post-hoc test defining significant differences in marks between each year group $(\mathrm{p}<0.05)$ using GraphPad Prism 6 software (GraphPad Software Inc, La Jolla, CA).

A questionnaire (available upon request) was developed and enabled students to provide voluntary written feedback (paper format) on the strengths and weaknesses of the teaching exercise at the end of the final week. Students knew in advance that feedback would be utilized for educational research. Students were also informed about the research questionnaire at the beginning of the final class. Written notice, stating the data collected may be used for publication purposes, was provided at the front of each questionnaire. The evaluation questionnaire comprised of 17 questions. Quantitative data was collected from 10 preformed questions derived from the five-point Likert scale ( $4=$ strongly agree to $0=$ strongly disagree). The remaining seven questions were open response, allowing students the opportunity to state what they liked and disliked about the teaching initiative. Skills development was evaluated by requesting students check the skills that they believe they had acquired from the class. Approval was obtained from the School of Pharmacy Research Ethics Committee to conduct this study.

\section{Findings}

The full cohort of 24 students completed the practical. The overall mean score (out of 20) in 2016 was $15.3(\mathrm{~S} . \mathrm{D} \pm 1.6)$ and $16.1(\mathrm{~S} . \mathrm{D} \pm 3.1)$ in 2015 (Table 5) with a range between 12.8 and 18. Only chloral hydrate suppositories demonstrated any statistical difference in mean scores. The 2016 group provided a significantly reduced mean score $(\mathrm{p}<0.01)$ compared to 2015 . There was no significant 
difference in the majority of scores for each product when comparing the 2015 and 2016 groups. The most common minor error, warranting a deduction of a score of one, was failure to recognize a legal error (e.g. incorrect equipment serial number/calibration date) in the master batch formula (2015: $36.4 \%, 2016: 23.1 \%)$. The most common major error, leading to a deduction of five from the final score, was incorrect calculation resulting in an inaccurate strength of active ingredient in the final product (2015: 16.5\%, 2016: 15.3\%). To evaluate skills development, students were requested to check the skills they believed they had acquired in the questionnaire distributed at the end of practical session (Table 6). For both year groups the majority of students $(>70 \%)$ indicated that they had acquired skills in areas directly related to the learning outcomes (Table 1). Research (2015: 54.5\%, 2016: 9\%), communication (2015: 0\%, 2016: 7.7\%) and teamwork (2015: 9.1\%, 2016: 27.2\%) skills scored less highly in feedback. Results of the Likert scale student evaluation questionnaire are outlined in Table 7 and Table 8 . All students agreed/strongly agreed that the practical was a useful teaching method and after participating they believed the development of formulation skills was important in order to have a successful career in pharmaceutical industry.

\section{Discussion}

The learning outcomes (Table 1) were defined after consideration of Bloom's, ${ }^{12}$ and Fink's Taxonomy of Learning, ${ }^{13}$ and Miller's triangle. ${ }^{14}$ These models demonstrate a higher level of cognitive learning is needed for teaching pharmaceutical formulation, with a focus on demonstrating knowledge via a "shows how" approach. Learning outcomes focused on higher level aims such as development of problem-solving and analytical skills. ${ }^{15}$ Learning outcomes and skill development from the perspective of the faculty member was determined by calculating the mean percentage deduction of marks across each product. The most common error was failure to recognize a legal error in the master batch formula leading to a minor deduction of one from the product score. Incorrect pharmaceutical calculation, leading to an incorrect strength of active ingredient in the final product, was the highest major error (deduction of 5). This indicated that legal checking skills and 
pharmaceutical calculations directly scored the lowest with regard to skills development. Chloral hydrate suppositories were the only product to demonstrate any significant difference $(\mathrm{p}<0.01)$ in mean scores when directly comparing 2016 (mean: 9.8 \pm 5.1 out of 20) and 2015 (mean: $15.8 \pm 2.4$ out of 20) results. The majority of students incorrectly calculated the quantity of suppository base and active drug required for formulating $6 \times 1 \mathrm{~g}$ suppositories as requested by the relevant master batch formula. This was the first instance the students had encountered $1 \mathrm{~g}$ suppositories and the majority manufactured $2 \mathrm{~g}$ suppositories in line with all other suppository products resulting in a deduction of 5 marks for incorrect calculations and 5 marks for incorrect quantities of raw materials in batch formula table. In future years we will relay the importance of checking the quantity and batch size of the formulation requested by the master batch formula within the introductory and product specific oral presentations (Table 2).

From the student feedback questionnaire, research, communication and teamwork skills scored less highly in terms of skills development for both year groups (Table 6). This is perhaps unsurprising given that students are instructed to work individually and are not allowed to discuss activities with their peers during class. The definition of research skills should also have been linked more succinctly with student's ability to utilize research texts and is best served under the skill of interpreting, analyzing and reporting data. Students possibly believed that true research relates directly to discovering new chemical entities or formulations (e.g. sustained release formulations).

For the CAPAs exercise, differences were demonstrated between the two year groups in relation to how acceptable the 10 minutes provided to complete each CAPAs product was. In $2015,81.9 \%$ of the 11 students agreed/strongly agreed that this was sufficient time. In 2016, 53.8\% of the 13 students disagreed that time allocated was sufficient. Staff involved in developing the practical believe that despite the relatively high numbers disagreeing with time allocated to CAPAs in 2016, it is important to retain time dependent pressure to replicate work-based practices whereby deadlines have to be met and decisions made regarding acceptance/rejection of batches in good time. It tasks students with activities they will encounter in professional practice creating a realistic environment for teaching. ${ }^{16} \mathrm{~A}$ limitation of CAPAs is that this is the first time the students have been involved in such an assessment 
exercise. Whilst there is no direct comparator to the CAPAs exercise it shares similarities to Objective Structured Clinical Examinations (OSCE), a teaching exercise used to assess clinical aptitude in a contextualized pharmacy environment. ${ }^{17}$ OSCEs and CAPAs are fundamental to improving the student's ability to spot legal errors and exercise professional judgement. CAPAs emphasize the importance of the master batch formula and formulation skills, mimicking work-based industrial scenarios. ${ }^{18}$ CAPAs allowed a different form of assessment to be introduced enabling the students to take on the role of the qualified person. In order to test a variety of learning outcomes an assortment of teaching exercises should be implemented as outlined by Shulman. ${ }^{19}$

The open-response section of the questionnaire provided a number of common themes. Across both year groups most students (54.1\%) expressed the practical was relevant to their future role within the pharmaceutical industry. The most negative theme (20.8\%) was a lack of time to make two products per laboratory session. Faculty members involved in the design and implementation of this teaching exercise believe the hypothesis to be proven correct and that pharmaceutical formulation and its skills can be effectively enhanced through a laboratory-based practical. The aims of the project were also achieved, in that a laboratory practical was designed, implemented, and evaluated successfully as a method for teaching undergraduate pharmaceutical science students about the importance of formulation and regulatory issues within the pharmaceutical industry. Faculty members involved in this project have been responsible for teaching in all aspects of pharmacy and pharmaceutical science..$^{17,20,21,22}$ It was difficult to incorporate a tableting practical into this session given the need for students to formulate simple to manufacture dosage forms within an individual student exercise. Tableting forms a component of the Industrial Pharmaceutics module coursework but as a separate group-based teaching exercise, recognizing not only the importance of tablets as the most widely accepted dosage form by patients but appreciating it is difficult to allow students to formulate these products on an individual basis due to time constraints and the expense of purchasing multiple tableting machines. Limitations were also encountered with assessing the quality of the final medicinal product. In industry such products would be assessed for characteristics such as strength 
and uniformity of content, in line with pharmacopoeial specifications. Medicinal product quality in our teaching exercise was limited to assessing the visual appearance of the product and its final mass. In practice pharmacopoeial assays would be developed to assess these specifications more accurately. ${ }^{23}$ This was difficult to perform within our teaching exercise due to the large variety of different drugs/formulations utilized within a relatively short, nine week time-scale. The importance of timely feedback for this continual assessment exercise was deemed more important than the development of individual assays to characterize product quality. Timely feedback enhances the student experience. ${ }^{24}$ If such assays could be introduced as a teaching exercise it would not only increase student's skills in relation to pharmaceutical analysis but also improve integration and overlap of curriculum content within the pharmaceutical sciences degree. ${ }^{24}$ This will be explored in future as the degree develops.

\section{Summary}

We designed and evaluated a laboratory-scale pharmaceutical formulation practical for pharmaceutical science students to help them develop work-based skills related to industrial pharmacy. All 24 students believed after participating in this exercise they are fully capable of demonstrating the key skills required to manufacture the dosage forms outlined in this practical session. The laboratory class was relatively easy to design and implement. Overall it served as an effective teaching tool for the delivery of industrial pharmaceutical formulation enabling the hypothesis to be accepted. This teaching exercise has the potential to be used as a teaching tool not only within the pharmacy degree but as a continual professional development exercise for formulation scientists or within other university programs.

\section{References}

1. General Pharmaceutical Council. Future pharmacists: Standards for the initial education and training for pharmacists. 2011: 1-64. 
2. Accreditation Council for Pharmacy Education. Accreditation standards and guidelines for the professional program in pharmacy leading to the doctor of pharmacy degree. 2016: 1-39.

3. Inspection, Enforcement and Standards Division of the Medicines and Healthcare Products Regulatory Agency. Rules and Guidance for Pharmaceutical Manufacturers and Distributors. 9th ed. London,UK: Pharmaceutical Press; 2015.

4. Lizzio A, Wilson K. Feedback on assessment: students' perceptions of quality and effectiveness. Assess Eval High Educ. 2008;33:263-275.

5. Brown G. Assessment: A Guide for Lecturers. Assessment Series No.3. LTSN Generic Centre; 2001: 1-28.

6. Medicines and Healthcare Products Regulatory Agency. Best practice guidance on the labelling and packaging of medicines. 2015: 1-16.

7. Health and Safety Executive. Control of Substances Hazardous to Health. The Control of Substances Hazardous to Health Regulations 2002. Approved Code of Practice and Guidance. 6th ed. Suffolk UK: HSE Books; 2013.

8. International Conference on Harmonization Working Group. ICH harmonized tripartite guidance Q9 quality risk management. 2005: 1-23.

9. International Conference on Harmonization Working Group. ICH harmonized tripartite guidance Q10 pharmaceutical quality system. 2008: 1-26.

10. Inspection, Enforcement and Standards Division of the Medicines and Healthcare Products Regulatory Agency. Rules and guidance for pharmaceutical manufacturers and distributors. 9th ed. London, UK: Pharmaceutical Press; 2015.

11. Yu LX, Amidon G, Khan MA, et al. Understanding pharmaceutical quality by design. AAPS J. 2014;16(4):771-783. 
12. Bloom BS. Taxonomy of Educational Objectives. The Classification of Educational Goals.

Handbook I: Cognitive Domain. New York, NY: McKay; 1956.

13. Fink LD. Creating Significant Learning Experiences. An Intergrated Approach to Designing College Courses. San Francisco, CA: Jossey-Bass; 2003.

14. Miller GE. The assessment of clinical skills/competence/performance. Acad Med. 1990;65 (9 Suppl):S45-S47.

15. Gibbs G, Gregory R, Moore I. Teaching more students: 7 - labs and practicals with more students and fewer resources. Laboratory practicals to teach pharmacy. 1997: 1-28.

16. Hammick M, Reid C. Contemporary Issues in Assessment and Health Sciences and Practice Education. London, UK: Higher Education Academy; 2010.

17. Hughes F, Barry J, Belaid L, et al. Development of an objective structured clinical examination (OSCE) to assess formulation and extemporaneous dispensing skills in MPharm undergraduates. Pharmacy Education. 2013;13(1):7-14.

18. Lemanski T, Mewis R, Overton T. An introduction to work-based learning. London, UK: Higher Education Academy; 2011.

19. Shulman LS. Course anatomy: The dissection and analysis of knowledge through teaching. In: Hutchings P, ed. The Course Portfolio: How Instructors Can Examine their Teaching to Advance Practice and Improve Student Learning. Washington DC, USA: American Association for Higher Education; 1998:5-12.

20. Donnelly RF, McCague PJ, McPhillips H, et al. Design and evaluation of a "pharmacists in schools" community outreach programme: A pilot study. Pharmacy Education. 2010;10:129-137.

21. Hanna LA, Barry J, Donnelly R, et al. Using debate to teach pharmacy students about ethical issues. Am J Pharm Educ. 2014;78(3): article 57. 
22. Laverty G, Hanna LA, Haughey S, Hughes C. Developing entrepreneurial skills in pharmacy students. Am J Pharm Educ. 2015;79(7): article 106.

23. British Pharmacopoeia Commission. Monographs: Medicinal and pharmaceutical substances. In: British Pharmacopoeia 2016. London, UK: The Stationery Office MHRA; 2016.

24. Gibbs G, Simpson C. Conditions under which assessment supports learning. Learning and Teaching in Higher Education. 2004;1:3-31.

25. Husband AK, Todd A, Fulton J. Integrating science and practice in pharmacy curricula. Am J Pharm Educ. 2014;78(3): article 63. 